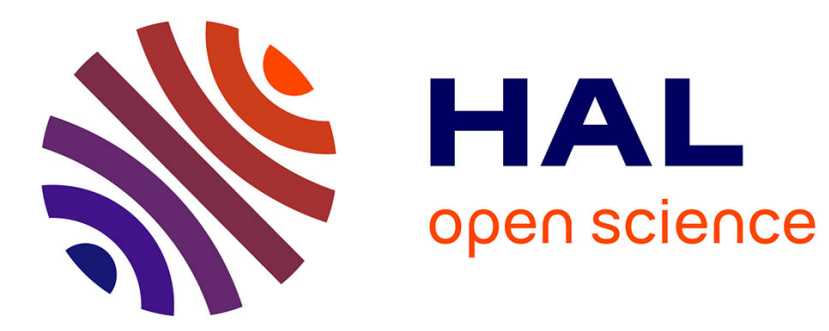

\title{
Melanocortin 5 receptor activates ERK1/2 through a PI3K-regulated signaling mechanism
}

Adriana R. Rodrigues, Duarte Pignatelli, Henrique Almeida, Alexandra M.

Gouveia

\section{- To cite this version:}

Adriana R. Rodrigues, Duarte Pignatelli, Henrique Almeida, Alexandra M. Gouveia. Melanocortin 5 receptor activates ERK1/2 through a PI3K-regulated signaling mechanism. Molecular and Cellular Endocrinology, 2009, 303 (1-2), pp.74. 10.1016/j.mce.2009.01.014 . hal-00499111

\section{HAL Id: hal-00499111 https://hal.science/hal-00499111}

Submitted on 9 Jul 2010

HAL is a multi-disciplinary open access archive for the deposit and dissemination of scientific research documents, whether they are published or not. The documents may come from teaching and research institutions in France or abroad, or from public or private research centers.
L'archive ouverte pluridisciplinaire HAL, est destinée au dépôt et à la diffusion de documents scientifiques de niveau recherche, publiés ou non, émanant des établissements d'enseignement et de recherche français ou étrangers, des laboratoires publics ou privés. 


\section{Accepted Manuscript}

Title: Melanocortin 5 receptor activates ERK1/2 through a PI3K-regulated signaling mechanism

Authors: Adriana R. Rodrigues, Duarte Pignatelli, Henrique Almeida, Alexandra M. Gouveia

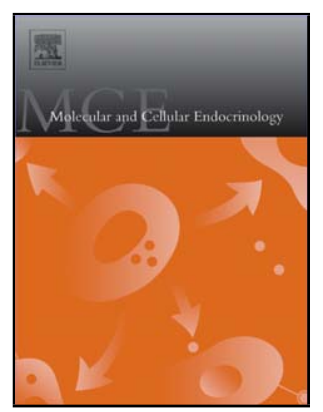

PII:

S0303-7207(09)00063-X

DOI: doi:10.1016/j.mce.2009.01.014

Reference: MCE 7130

To appear in: Molecular and Cellular Endocrinology

Received date: 26-9-2008

Revised date: 19-1-2009

Accepted date: 20-1-2009

Please cite this article as: Rodrigues, A.R., Pignatelli, D., Almeida, H., Gouveia, A.M., Melanocortin 5 receptor activates ERK1/2 through a PI3Kregulated signaling mechanism, Molecular and Cellular Endocrinology (2008), doi:10.1016/j.mce.2009.01.014

This is a PDF file of an unedited manuscript that has been accepted for publication. As a service to our customers we are providing this early version of the manuscript. The manuscript will undergo copyediting, typesetting, and review of the resulting proof before it is published in its final form. Please note that during the production process errors may be discovered which could affect the content, and all legal disclaimers that apply to the journal pertain. 
Melanocortin 5 receptor activates ERK1/2 through a PI3K-regulated signaling mechanism

Adriana R Rodrigues ${ }^{1,2}$, Duarte Pignatelli ${ }^{1,3}$, Henrique Almeida ${ }^{1,2}$ and Alexandra M Gouveia $^{1,2,4}$

${ }^{1}$ Laboratory of Cell and Molecular Biology, Faculty of Medicine of Porto, Portugal; ${ }^{2}$ Institute for Molecular and Cell Biology, Porto, Portugal; ${ }^{3}$ Department of Endocrinology S. João Hospital and Institute of Molecular Pathology and Immunology, Porto, Portugal; ${ }^{4}$ Faculty of Nutrition and Food Sciences of the University of Porto, Portugal

Corresponding author:

Name: Alexandra Gouveia

Address- Laboratório de Biologia Celular e Molecular da Faculdade de Medicina da Universidade do Porto, Alameda Prof. Hernani Monteiro, 4200-319 Porto

Telephone: +351225513654

Fax: +351225513655

Email: agouveia@med.up.pt 
Summary

Melanocortin 5 receptor (MC5R) is a G-protein coupled receptor (GPCR) with high affinity for $\alpha-\mathrm{MSH}$. To unravel some of the downstream cell-signaling pathways activated by this receptor, HEK293 cells were transiently and stably transfected with a vector encoding green fluorescent protein (GFP)-tagged MC5R. In these cells the receptor was correctly addressed to the cell surface and was functional, as shown by the MC5R-induced formation of intracellular cAMP. In fact, the MC5R agonist $\alpha$-MSH induced a 10 or 16 fold increase (transient or stable cells, respectively) above the cAMP levels found in unstimulated cells. Moreover, in cells stably expressing MC5R-GFP, $\alpha-$ MSH promoted ERK1/2 phosphorylation in a dose-dependent manner (EC50=7.3nM) with the maximal effect occurring after $5 \mathrm{~min}$ of agonist incubation. The signaling pathway conveyed through ERK1/2 is not linked to cAMP, since the phosphorylation of these kinases is unchanged by the inhibition of adenylyl cyclase. Also, ERK1/2 activation is not significantly affected by PKA, PKC and Akt/PKB specific inhibitors. However, $\alpha$-MSH-induced ERK1/2 activation is abolished by the PI3K inhibitors wortmannin and LY294002. Altogether, these findings demonstrate that MC5R signals through a PI3K-regulated Akt-independent pathway leading to downstream activation of ERK1/2. The involvement of these MAPK suggests that MC5R could be implicated in cellular proliferation or differentiation mechanisms.

Keywords: Melanocortin 5 receptor; PI3K; ERK1/2; $\alpha-\mathrm{MSH}$; GPCR; Akt/PKB 
Introduction

The melanocortin 5 receptor belongs to a five member-family of $\mathrm{G}$ protein coupled receptors (MC1R-MC5R) and has a preferential affinity for $\alpha$-melanocytestimulating hormone $(\alpha-\mathrm{MSH})$, followed by adrenocorticotropic hormone (ACTH) and $\beta$-MSH (Getting, 2006). MC5R has a broad tissue distribution in almost all eukaryotic organisms. In fact, northern blot analysis, RT-PCR or ribonuclease protection assays have shown MC5R expression in brain, sebaceous glands, adrenal gland, kidney, lymph nodes, uterus, esophagus, spleen, thymus, testis, ovary, muscle, adipocytes, mast cells, lymphocytes, liver, lung, mammary glands, bone marrow, skin, stomach, duodenum and exocrine glands (lacrimal, prostate, seminal, pancreatic, preputial, Harderian) (for review see Millington, 2006; Catania et al., 2004).

The physiological role of MC5R is still a matter of debate, but targeted deletion of the receptor resulted in sebaceous gland deficient secretion (Chen et al., 1997). MC5R function also seems to be related with stress response. Indeed, it was observed an up-regulation of MC5R on the rat adrenal cortex as a consequence of a chronic stress (Pignatelli et al., 2000).

Regarding the signaling mechanism of the melanocortin receptors (MCRs), it is accepted that after agonist activation, the G $\alpha$ proteins stimulate cAMP production via adenylyl cyclase leading to protein kinase A (PKA) activation. Although this is the most studied signaling pathway, it was also described that stimulation of some MCRs by $\alpha-$ MSH activates the mitogen-activated protein kinases family (MAPK), NF-kB and JAK/STAT signaling cascades (Catania et al., 2004). In fact, in MC3R and MC4R transfectants, NDP- $\alpha$-MSH induces extracellular signal-regulated kinase 1 and 2 (ERK1/2) phosphorylation via phosphatidylinositol 3-kinase (PI3K) (Vongs et al., 2004, Chai et al., 2007). A slightly different result was obtained with another agonist of these receptors such as melanotan II, which induces an increase of phospho-MAPK levels in COS-1 cells transfected with MC4R but not with MC3R (Daniels et al., 2003). Furthermore, it was recently demonstrated that MC2R mediates an ACTH-induced ERK1/2 activation in H295R cells by a mechanism independent of PKA (Janes et al., 2008). ACTH also induces a rapid phosphorylation of p38 kinase and ERKs in human keratinocytes (Park et al., 2007) and modulates ERK activation in adrenal gland (Ferreira et al., 2004). There is also evidence that $\alpha$-MSH binding to MC5R activates the JAK/STAT pathway in lymphocytes (Buggy, 1998) and increases the production of cAMP and calcium in HEK293 cells stably transfected with MC5R (Hoogduijn et al., 2002; Mountjoy et al., 2001).

Nevertheless, despite the several studies regarding the involvement of diverse pathways in MCRs activation, the signaling mechanisms activated by MC5R are still poorly understood. In this study, we present evidence that in HEK293 cells expressing MC5R-GFP, $\alpha$-MSH induces the activation of ERK1/2 mainly by a mechanism that requires PI3K but seems to be independent of adenylyl cyclase and PKA, protein kinase $\mathrm{B}$ or $\mathrm{Akt}(\mathrm{PKB} / \mathrm{Akt})$ and protein kinase $\mathrm{C}(\mathrm{PKC})$. 
Materials and Methods

Materials

Forskolin, $\alpha-\mathrm{MSH}, \mathrm{N}-[2-(\mathrm{p}$-bromocinnamylamino)ethyl]-5-isoquinoline sulfonamide (H-89), 3-isobutyl-methyl-xantine (IBMX), 2-(4-Morpholinyl)-8-phenyl-4H-1benzopyran-4-one (LY294002), 2',5'-dideoxyadenosine (2',5'-DDA) and wortmannin were obtained from Sigma-Aldrich. DMEM/Ham's F-12 medium, glutamine and fetal bovine serum were purchased from Biochrom AG. 2-[1-(3-Dimethylaminopropyl)-1Hindol-3-yl]-3-(1H-indol-3-yl) maleimide (GF109203X) and Akt inhibitor VIII were purchased from Calbiochem.

Constructs

Total RNA from Wistar Rattus norvergicus adrenal gland was isolated using the RNeasy ${ }^{\circledR}$ Mini kit (Qiagen) following the manufacturer instructions. The residual genomic DNA which could be contaminating the RNA was degraded with a RNase-free DNAse (Qiagen). The entire open reading frame (ORF) of rat MC5R was amplified by RT-PCR using the specific primers 5'-ggaagatctgccaccatgaactcctcgtctcac-3' and 5'ccggaattctatacctgccaaggagcgta-3' which were designed in accordance with the published sequence (Griffon et al., 1994). The rat MC5R ORF was cloned in the pCR2.1-TOPO vector (Invitrogen ${ }^{\mathrm{TM}}$ ) following the manufacturer instructions. The resultant recombinant plasmid was digested with EcoRI and $B g l$ II restriction enzymes and the MC5R insertion was sub-cloned in the eukaryotic expression vector $\mathrm{pEGFP-N1}$ (Clontech). To produce the non-tagged MC5R, the rat MC5R ORF was amplified by RT-PCR using the primers 5'-ggaaagcttgccaccatgaactcctcgtctcac-3' and 5'ccgggatccatacctgccaaggagcgta-3' and was cloned in the $\mathrm{pCR}^{\circledR}$-Blunt II-Topo ${ }^{\circledR}$ vector (Invitrogen ${ }^{\mathrm{TM}}$ ). The MC5R insert was obtained by digestion of the recombinant plasmid with HindIII and BamHI restriction enzymes and was sub-cloned on pcDNA3.0 vector (Invitrogen ${ }^{\mathrm{TM}}$ ). The pMC5R-EGFP and pMC5R-pcDNA vectors were subsequently sequenced to insure that no errors were induced by PCR reactions. The isolation of pure plasmids was performed using the StrataPrep ${ }^{\circledR}$ EF Plasmid Midiprep Kit (Stratagene) and these DNAs were used on transfection experiments.

Cell culture and transfection

HEK293 cells were cultured in DMEM/Ham's F-12 medium supplemented with 10\% fetal bovine serum and $2 \mathrm{mM}$ glutamine in $5 \% \mathrm{CO}_{2} /$ humified atmosphere at $37^{\circ} \mathrm{C}$ until $70-80 \%$ confluence was attained for use. HEK293 cells were transiently transfected with $0,4 \mu \mathrm{g}$ of pMC5R-EGFP, pMC5R-pcDNA or pEGFP-N1 alone, as a control, in serum free medium for $16 \mathrm{~h}$ using Effectene Reagent (Qiagen), as recommended by manufacturer instructions. HEK293 cells stably expressing MC5R-GFP or GFP alone were selected by the addition of $0,6 \mu \mathrm{g} / \mu \mathrm{l}$ Geneticin (GIBCO).

RT-PCR analysis

The isolation and purification of total RNA from HEK293 cells transfected with pMC5R-EGFP or pEGFP-N1 and the MC5R RT-PCR reactions were performed as described above. As control a 496 bp sequence of human GAPDH was amplified using the primers pair 5' -ggtgaaggtcggagtcaacg-3' and 5'-caaagttgtcatggatgacc-3'.

Cell treatment

HEK293 cells expressing GFP, MC5R or MC5R-GFP were incubated in culture medium without serum for $16 \mathrm{~h}$. Two hours prior experiments the medium was replaced. 
Then cells were treated with various concentrations of $\alpha-\mathrm{MSH}$ at $37^{\circ} \mathrm{C}$ for the length of time indicated in Results. For studies of inhibition of the different signaling pathways, several drugs were tested at concentrations that were based on cellular half-maximal inhibitory concentration (IC50) values derived from the available literature (Davies et al., 2000). Thus, cells stably expressing GFP or MC5R-GFP were incubated with vehicle or with different concentrations of the following inhibitors (2',5'-DDA, H-89, GF109203X, wortmannin, LY294002 and Akt inhibitor VIII), for 30min, before addition of $1 \mu \mathrm{M} \alpha-\mathrm{MSH}$ during $5 \mathrm{~min}$. Then, cells were washed with ice-cold PBS and lysed with a cell lysis buffer $(50 \mathrm{mM}$ Tris- $\mathrm{HCl} \mathrm{pH} 7.6,10 \mathrm{mM} \mathrm{NaCl}, 5 \mathrm{mM}$ EDTA and $0.5 \%$ Triton $\mathrm{X}-100)$ supplemented with phosphatase and protease inhibitor cocktails (Sigma-Aldrich). Lysates were sonicated and the protein concentrations were determined using the Bradford protein assay (BioRad).

Fluorescence microscopy

To detect the GFP-tagged MC5R expression and cellular distribution, transient or stable transfected HEK293 cells were washed with PBS and fixed with 4\% formaldehyde for $20 \mathrm{~min}$ at room temperature. Images were captured with an ApoTome fluorescence microscope (Zeiss).

cAMP assay

After serum starvation, cells transiently or stably expressing MC5R-GFP or GFP were treated for $10 \mathrm{~min}$ with $50 \mu \mathrm{M}$ forskolin or $1 \mu \mathrm{M} \alpha-\mathrm{MSH}$ in the presence of $1 \mathrm{mM}$ IBMX (phosphodiesterase inhibitor) at $37^{\circ} \mathrm{C}$. The medium was removed and cells were immediately lysed in $0.1 \mathrm{M} \mathrm{HCl}$. Intracellular cAMP was quantified following the manufacturer instructions using the enzyme immunoassay kit from Sigma-Aldrich.

Western-blotting analysis

Twenty micrograms of cell lysate were separated in a $10 \%$ polyacrylamide gel using the Laemmli discontinuous buffer system (Laemmli, 1970) and transferred onto a nitrocellulose membrane (BioRad). The blots were blocked with 5\% non-fat dried milk in TBSt (Tris buffer saline with $0.1 \%$ Tween-20) and incubated with anti phosphoERK1/2, phospho-Akt (Ser473) or Akt antibodies (Cell Signaling) 1:1000 in 10\% normal goat serum in TBSt, overnight at $4^{\circ} \mathrm{C}$. After thorough washing, the anti-ERK1/2 and Akt (phospho and total) primary antibodies were detected with anti-rabbit or antimouse-HRP conjugates (1:5000), respectively, for $1 \mathrm{~h}$ at room temperature. The bound antibodies were detected using enhanced chemiluminescence (SuperSignal West Pico Chemiluminescent Substrate, Pierce) and exposed to Pierce CL-XPosure film. Antibodies against pERK1/2 were then stripped incubating the membranes with $10 \%$ SDS for $30 \mathrm{~min}$ at room temperature. Following blocking, the membranes were incubated overnight with anti-ERK1/2 antibodies (Cell Signaling), 1:1000 at $4{ }^{\circ} \mathrm{C}$. The signal detection was performed as previously described.

Data analysis

Digital images of Western blots were analyzed by densitometry using Scion Image and the dose-response analysis was performed using GraphPad Prism 5 software. Each result represents the mean \pm S.D. of at least three experiments. All data were analyzed using the Student's $t$ test or one-way ANOVA followed by Bonferroni's post hoc test. 
Results

\section{Expression of MC5R-GFP in HEK293 cells}

The study of MC5R-mediated signal transduction mechanisms was undertaken by use of an heterologous expression system. HEK293 cells were transiently and stably transfected with a cDNA construct encoding the rat MC5R fused to GFP. This system was chosen because primary cell cultures expressing MC5R have a multitude of other melanocortin receptors, which also respond to the MC5R agonist $\alpha-\mathrm{MSH}$. Otherwise, HEK293 cells have been used by several authors to over-express MC5R (although in a non-tagged form) and in this system MC5R revealed to have properties similar to other melanocortin receptors (Hoogduijn et al., 2002; Mountjoy et al., 2001).

MC5R expression was first characterized by RT-PCR analysis in cell transfectants. HEK293 cells transiently transfected with the pMC5R-EGFP, as well as the stably transfected clone, expressed MC5R mRNA (Fig 1A).

In this cell system, MC5R was expressed as a GFP fusion protein, with the fluorescent tag located at its C-terminal, which enables the study of the receptor localization by fluorescence microscopy. A MC5R construct containing the GFP at the $\mathrm{N}$-terminus was also produced but fluorescence microscopy analysis revealed that the protein was poorly expressed and strongly retained inside the cell (data not shown). Cells transfected with the empty vector pEGFPN1 revealed a diffuse green fluorescence distributed through-out the cell (Fig 1B). On the contrary, MC5R-GFP was detected at cell surface suggesting that the receptor was correctly targeted to the plasma membrane (Fig 1C, D and E). A high and distinct cytoplasmic fluorescence was also visualized in pMC5R-EGFP transfected cells resembling a Golgi-apparatus and/or endoplasmic reticulum localization. In stably transfected cells, the receptor did not accumulate so strongly on intracellular compartments and MC5R-containing secretory vesicles were now clearly distinguishable (Fig 1D, E). This data confirms that at least part of the MC5R-GFP was correctly folded and well translocated to the plasma membrane both in transiently and stably transfected cells.

\section{a-MSH-mediated cAMP production in MC5R-GFP expressing HEK293 cells}

To confirm the functionality of the MC5R-GFP located at the plasma membrane, we tested for $\alpha-\mathrm{MSH}$-induced formation of intracellular cAMP. As illustrated in Fig 2, pEGFPN1-transfected HEK293 cells do not respond to $\alpha$-MSH stimulation, which confirms the absence of endogenous melanocortin receptors expression in this cell system. However, when these cells are treated with the adenylyl cyclase activator forskolin there is a strong stimulation of the cAMP production (about 400 fold above the control). The incubation of transiently and stably transfected cells for 10min with MC5R agonist results in a 10 or 16 fold increase, respectively, above the cAMP levels found in un-stimulated cells. In conclusion, stable cell cultures respond slightly better than transient transfected cells and, for this reason, were used on the subsequent experiments.

\section{Activation of ERK1/2 in stably MC5R-GFP transfected HEK293 cells}

Although GPCRs classically signal through Gas-cAMP-PKA pathway, some alternative signal transduction mechanisms have been described (for review see New and Wong, 2007). Therefore, the involvement of the MAP-kinase cascades on MC5R- 
mediated signal was investigated. MC5R-GFP and GFP expressing HEK293 cells were incubated with $\alpha-\mathrm{MSH}$ (Fig 3A, lanes + ) or with vehicle (Fig 3A, lanes -) and the stimulation of ERK1/2 was assessed by western-blotting analysis. In pEGFPN1 transfected cells, $\alpha-\mathrm{MSH}$ did not activate ERK1/2 (Fig 3A, lanes GFP). However both ERK1 and ERK2 were strongly and specifically phosphorylated by $\alpha$-MSH in the presence of MC5R-GFP (Fig 3A, lanes MC5R-GFP). In order to exclude some nonspecific effect of the GFP tag on the MC5R functional mechanism, the non-tagged MC5R was transiently expressed on HEK293 cells. As for MC5R-GFP, ERK1/2 was activated after $\alpha$-MSH stimulation of the MC5R expressing cells (Fig 3A, lanes MC5R). Though the absolute amount of phosphorylated ERK2 was greater than that of ERK1, the relative increases in phosphorylated proteins between control and $\alpha$-MSH stimulated cells were found to be similar. For this reason, the quantification of ERK1/2 phosphorylation was jointly performed in the following experiments.

To determine if ERK1/2 activation occurs in a dose-responsive manner, MC5RGFP expressing cells were incubated with increasing concentrations of $\alpha$-MSH ( $1 \mathrm{nM}$ to $10 \mu \mathrm{M})($ Fig 3B). The analysis of ERK1/2 phosphorylation by western-blotting revealed that it was dose-dependent with an EC50 of $7.3 \mathrm{nM}$, in agreement with published data for hMC5R-stimulated cAMP production (Bednarek et al., 2007). The maximum ERK1/2 activation was obtained with $1 \mu \mathrm{M} \alpha-\mathrm{MSH}$, with an increase of around 8 -fold above the basal levels.

For the time-course study, MC5R-GFP transfected cells were incubated with $1 \mu \mathrm{M} \alpha$-MSH for several time-points (5-180min). Western-blotting analysis revealed that ERK $1 / 2$ is promptly activated, with maximal intensity $5 \mathrm{~min}$ after stimulus (Fig 3C). A cyclic pattern or a sustained effect may operate on ERK1/2 signaling by $\alpha$-MSH since $180 \mathrm{~min}$ after stimulus, pMC5R-EGFP transfected cells maintained ERK1/2 phosphorylated levels higher than control. In subsequent experiments, cells were treated with $1 \mu \mathrm{M} \alpha-\mathrm{MSH}$ for $5 \mathrm{~min}$.

\section{Signaling requirements for MC5R-mediated ERK1/2 activation}

As described before, when cells stably expressing MC5R are stimulated with $\alpha-$ MSH there is an increase of cAMP production. cAMP in turn activates the cAMPdependent protein kinase PKA. To determine if activation of adenylyl cyclase is fundamental to MC5R-mediated ERK1/2 phosphorylation, HEK293 cells stably expressing the receptor were incubated with $2^{\prime}, 5^{\prime}$-DDA $(10 \mu \mathrm{M}-1 \mathrm{mM})$ before $\alpha$-MSH stimulation (see Materials and Methods). As shown if Fig 4A, the inhibition of adenylyl cyclase has no effect on $\alpha$-MSH-induced ERK1/2 activation. The involvement of PKA was also addressed by pre-treating MC5R-GFP expressing cells with a PKA specific inhibitor, H-89 (10 and $100 \mu \mathrm{M})$. Although western-blotting analysis shows a slight decrease on ERK1/2 activation after PKA inhibition with $10 \mu \mathrm{M} \mathrm{H}-89$, this difference is not statistically significant (Fig 4B). This H-89 concentration was reported as being sufficient to block PKA activity in HEK293 cells, as indicated by the abolishment of ERK1/2 phosphorylation (Gao et al., 1999). The higher H-89 concentration used $(100 \mu \mathrm{M})$ induces an intracellular unspecific inhibition, since controls are also affected by this inhibitor. These results demonstrate that cAMP and PKA are not fundamental for the MC5R-induced phosphorylation of ERK1/2.

The role of other second-messenger-dependent kinases, such as PKC, in MC5Rmediated ERK1/2 phosphorylation was also tested. The PKC inhibitor GF109203X (5 and $10 \mu \mathrm{M}$ ) was added to cell cultures $30 \mathrm{~min}$ prior stimulation with $\alpha$-MSH. As 
illustrated in Fig 5, the inhibition of PKC also does not interfere with ERK1/2 phosphorylation after treatment of stably transfected cells with $\alpha$-MSH.

The next step in this work involved the analysis of the PI3K/Akt signaling pathway on MC5R-induced ERK1/2 activation. With this purpose, pre-treatment of cells with wortmannin $(10 \mathrm{nM}-1 \mu \mathrm{M})$ or LY294002 $(10-100 \mu \mathrm{M})$, two PI3K inhibitors, markedly inhibited ERK1/2 phosphorylation. In fact, very low concentrations of these inhibitors (such as $10 \mathrm{~nm}$ for wortmannin and $10 \mu \mathrm{M}$ for LY294002) were sufficient to significantly decrease ERK1/2 phosphorylation indicating that MC5R mediated ERK1/2 activation is conveyed through PI3K (Fig 6A and B). The use of two structurally unrelated inhibitors of the same kinase eliminates the possibility of a non-specific effect of the drugs in our cell-based system.

Although Akt acts as the main effector for PI3K, other Akt-independent effectors also play important roles in carrying out PI3K signaling. In fact, when MC5RGFP expressing cells are stimulated with $\alpha-\mathrm{MSH}$, the Akt phosphorylation levels remain similar to control (Fig 6A and $\mathrm{B}$ ). This result suggests that MC5R-mediated activation of ERK1/2 is independent of Akt/PKB phosphorylation. As expected, phospho-Akt levels are abolished with wortmannin and LY294002 treatment (Fig 6A and $\mathrm{B})$.

To confirm this last result, the effect of the Akt inhibitor VIII on ERK1/2 activation was tested. This inhibitor interacts with the pleckstrin homology domain of Akt preventing the conformational change required for phosphorylation of this kinase (Green et al., 2008). As shown in Fig 7, even high concentrations of this inhibitor $(50 \mu \mathrm{M})$ do not have any effect on MC5R-mediated ERK1/2 phosphorylation after $\alpha$ MSH stimulation. This result corroborates the evidence that MC5R signals through a PI3K-regulated but Akt independent pathway. 


\section{Discussion}

The expression of rat MC5R with a tag (GFP) at its C-terminus was successfully attained in HEK293 cells and, as far as we know, is reported here for the first time. Since we have used a cell line from human origin, the success of our data is explained by the high similarity of the rat and human MC5R primary sequence ( $82 \%$ of identity). Moreover, even though rat MC5R has a very short intracellular C-terminal tail (only 12 aminoacids), the attachment of a $27 \mathrm{kDa}$ GFP polypeptide to the receptor C-terminus does not impair its trafficking to the cell surface neither its ability to respond to $\alpha-\mathrm{MSH}$.

Interaction between GPCRs is multiple and complex. A significant number of these receptors are shown to form homo- or heterocomplexes, suggesting that oligomerization of GPCRs may be a quite general phenomenon. For instance, MC1R (Zanna et al., 2008; Mandrika et al., 2005; Sánchez-Laorden et al., 2006) and MC4R (Nickolls and Maki, 2006) have the ability to homodimerize and MC1R and MC3R form heterodimers when expressed in Cos-7 cells (Mandrika et al., 2005). Our results demonstrate that, in HEK293 cells, MC5R-GFP is correctly addressed to the cellsurface and is functionally active in the absence of other melanocortin receptors. Even though these results were obtained in an over-expression system, they suggest that MC5R function does not require heterodimerization with any other melanocortin receptor. If MC5R oligomerizes it should interact with itself or with other receptor from a different family of GPCRs.

The data in this paper show that, in addition to cAMP activation, the $\alpha-\mathrm{MSH}-$ stimulated MC5R induces the phosphorylation of ERK1/2 in a dose-dependent manner. The maximum level of ERK1/2 activation is obtained $5 \mathrm{~min}$ after stimulation and then $50 \%$ of activation remains even after $180 \mathrm{~min}$. Thus, it seems that MC5R induces a sustained ERK1/2 activation instead of a transient one. A sustained ERK1/2 response is generally related with the stabilization of immediate early genes-encoded transcription factors, such as c-fos, c-jun and c-myc, and results in an increase in target gene expression. At cellular level, ERK1/2 sustained responses are frequently associated with cell cycle progression, cellular transformation or differentiation (Murphy and Blenis, 2006). In fact, earlier reports have postulated a MC5R role in sebocyte (Zhang et al., 2006) and adipocyte (Cho et al., 2005) differentiation. Experiments are in progress to test these hypotheses in an endogenously expressing MC5R cell system, essential to attain the physiological role of the receptor.

Having established an ERK1/2 response to MC5R stimulation by $\alpha-\mathrm{MSH}$, we tried to identify the mechanism by which this signal occurs. The use of specific inhibitors for the adenylyl cyclase, PKA and PKC revealed that ERK1/2 activation is independent of the pathways in which these proteins are involved. However, the PI3K inhibitors wortmannin and LY294002 specifically abolished the ERK1/2 activation mediated by $\alpha$-MSH-MC5R-GFP. Classically, PI3K activation initiates a phosphorylation cascade leading to the activation of Akt. However the data obtained in this work indicates that ERK1/2 activation is dependent of PI3K but does not require Akt phosphorylation.

One of the mechanisms of lipid kinase PI3K activation by GPCRs involves a direct binding of G $\beta \gamma$ subunits and the small GTPase Ras to PI3K (Schwindinger and Robishaw, 2001). Additionally, GPCRs can also activate PI3K pathways via receptor tyrosine kinases or integrin transactivation. PI3K then initiates a phosphorylation cascade leading to B-Raf and finally to ERKs activation.

Surprisingly, it has been recently proposed that some GPCRs do not couple to G proteins and then are able to activate ERK $1 / 2$ by a $\mathrm{G}$ protein-independent signaling. In 
fact, Jak/STATs, Src-family tyrosine kinases, GRKs/ $\beta$-arrestins, and PDZ domaincontaining proteins have been suggested to relay signals from GPCRs, independent of $G$ proteins, which could result in ERK1/2 activation (Sun et al., 2007). The single report on MC5R signaling states that this receptor activates the Jak/STAT pathway on Blymphocytes (Buggy, 1998) but the involvement of the ERK $1 / 2$ signaling cascade is not referred. However, there is a strong possibility that the same receptor could activate different transduction pathways when bound to different agonists or when activated in different cell systems.

In conclusion, the present study demonstrates that, after $\alpha$-MSH activation, MC5R stimulates the PI3K and Raf/MEK/ERK signaling pathways in HEK293 cells. This pathway is cAMP-independent and does not involve PKA, PKC and Akt. We believe that the expression of the recombinant MC5R protein described here represents a useful tool for the biochemical characterization of the receptor, since no functional antibodies are available to this protein. Furthermore it will be of utmost importance in getting new insights on MC5R function and for the elucidation of the key signaling mechanisms transduced by this receptor.

\section{Acknowledgements}

We thank Carlos Reguenga and Célia Cruz for critical reading of the manuscript and scientific discussions. This work was supported by "Fundação Calouste Gulbenkian". Gouveia AM and Rodrigues AR were also supported by POCI 2010, FSE and "Fundação para a Ciência e Tecnologia" (SFRH/BPD/34280/2006 and SFRH/BD/41024/2007, respectively). 


\section{Legend to Figures}

Fig 1. MC5R-GFP expression pattern in transiently and stably transfected HEK293 cells.

A. RT-PCR analysis of MC5R expression was performed in pEGFPN1 (GFP) and in transiently and stably pMC5R-EGFP transfected cells (MC5R-T and MC5R-S, respectively). Lanes (-) are controls without reversed transcription. HEK293 cells transiently expressing GFP (B) or MC5R-GFP (C) and stably transfected with pMC5REGFP (D and E) were observed with ApoTome fluorescence microscopy. Scale bar: $10 \mu \mathrm{m}$.

Fig 2. Intracellular cAMP production.

HEK293 cells expressing GFP and transiently or stably expressing MC5R-GFP (MC5R-T and MC5R-S, respectively) were mock-treated (control) or incubated for $10 \mathrm{~min}$ with $1 \mu \mathrm{M} \alpha-\mathrm{MSH}$ or $50 \mu \mathrm{M}$ forskolin in the presence of $1 \mathrm{mM}$ IBMX. Cells were immediately lysed and the cAMP content was quantified using a competitive enzyme immunoassay kit. The data are expressed as fold increase over control cAMP levels. Statistical analysis was performed by two-tailed Student's $t$ test $(* P<0.05 ; * * * P<0.001$, versus control).

Fig 3. $\alpha$-MSH induces ERK1/2 phosphorylation in HEK293 cells expressing MC5RGFP.

After serum depletion, HEK293 cells expressing MC5R-GFP, MC5R or GFP alone were mock-treated, lanes (-), or incubated with $1 \mu \mathrm{M} \alpha-\mathrm{MSH}$, lanes $(+)$, for $5 \mathrm{~min}(\mathrm{~A})$. For dose-response analysis, MC5R-GFP expressing cells were serum-depleted and incubated for $5 \mathrm{~min}$ with several concentrations of $\alpha$-MSH (ranging from $1 \mathrm{nM}$ to $10 \mu \mathrm{M}$ ) (B). In the kinetic analysis, cells expressing MC5R-GFP were treated with $1 \mu \mathrm{M} \alpha-\mathrm{MSH}$ for $5,10,30,60,120$ and $180 \mathrm{~min}(\mathrm{C})$. In all blots, $20 \mu \mathrm{g}$ of total protein were analyzed. ERK1/2 phosphorylation was determined using anti-phospho-ERK1/2 antibody. Then, blots were stripped and reblotted with an anti-total ERK1/2 antibody to determine the protein loading. Densitometry analysis of phospho and total ERK1/2 was performed. The data are expressed as fold increase over control phospho/total ERK1/2 levels. Asterisks indicate groups that are statistically significant from controls using two-tailed Student's $t$ test $(* * P<0.01 ; * * * P<0.001)$.

Fig 4. cAMP and PKA are not involved in MC5R-induced ERK1/2 activation Cells expressing MC5R-GFP were serum depleted for $16 \mathrm{~h}$ and mock-treated or incubated with several concentrations of the adenylyl cyclase inhibitor 2',5'-DDA $(10 \mu \mathrm{M}-1 \mathrm{mM})(\mathrm{A})$ or the PKA inhibitor $\mathrm{H}-89(10$ and $100 \mu \mathrm{M})(\mathrm{B}), 30 \mathrm{~min}$ prior incubation with $\alpha-\mathrm{MSH}$. Then cells were harvested and $20 \mu \mathrm{g}$ of total protein was analyzed by western-blotting using the anti-phospho and total ERK1/2 antibodies. Densitometry analysis of the results was performed. The data are expressed as fold increase over mock-treated phospho/total ERK1/2. Statistical significance was calculated using a one-way ANOVA followed by Bonferroni's post hoc test (ns - not significant for $P=1$ ).

Fig 5. PKC is not linked to MC5R-mediated ERK1/2 phosphorylation

MC5R-GFP expressing cells were incubated with $5 \mu \mathrm{M}$ or $10 \mu \mathrm{M}$ of the PKC inhibitor GF109203X. Thirty minutes later, cells were stimulated with $1 \mu \mathrm{M} \alpha-\mathrm{MSH}$. The levels 
of phospho and total-ERK1/2 were determined by western-blotting and data analysis was performed as described in the legend to figure 4 (ns - not significant for $P=1$ ).

Fig 6. MC5R-mediated ERK1/2 activation is conveyed through PI3K

The role of PI3K on MC5R signaling was analyzed by incubating HEK293 cells expressing this receptor with two specific inhibitors of PI3K: wortmannin (10nM-1 $\mu \mathrm{m})$

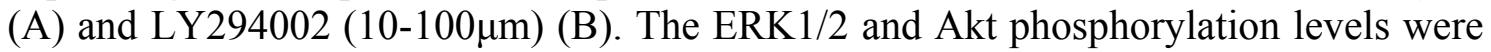
determined by western-blotting. The ERK1/2 and Akt total levels were used to normalize the protein loading. Asterisks indicate groups that are statistically significant from stimulated cells in the absence of inhibitor using a one-way ANOVA followed by Bonferroni's post hoc test $(* * P<0.01 ; * * * P<0.001)$. ns - not significant for $P=1$.

Fig 7. MC5R-mediated ERK1/2 activation is Akt independent HEK293 cells expressing MC5R-GFP were incubated with the Akt inhibitor VIII (1$50 \mu \mathrm{m}) 30 \mathrm{~min}$ before $\alpha$-MSH stimulation. The ERK1/2 and Akt phosphorylation levels were determined by western-blotting. The ERK1/2 and Akt total levels were used to normalize the protein loading. Statistical significance was calculated using a one-way ANOVA followed by Bonferroni's post hoc test (ns - not significant for $P=1$ ). 


\section{References}

Bednarek, M.A., MacNeil, T., Tang, R., Fong, T.M., Cabello, M.A., Maroto, M., Teran, A., 2007. Potent and selective agonists of alpha-melanotropin (alphaMSH) action at human melanocortin receptor 5; linear analogs of alpha-melanotropin. Peptides 28(5), 1020-1028

Buggy, J.J., 1998. Binding of alpha-melanocyte-stimulating hormone to its G-proteincoupled receptor on B-lymphocytes activates the Jak/STAT pathway. Biochem. J. 331, 211-216.

Catania, A., Gatti, S., Colombo, G., Lipton, J.M., 2004. Targeting melanocortin receptors as a novel strategy to control inflammation. Pharmacol. Rev. 56(1), 1-29.

Chai, B., Li, J.Y., Zhang, W., Ammori, J.B., Mulholland, M.W., 2007. Melanocortin-3 receptor activates MAP kinase via PI3 kinase. Regul. Pept. 139(1-3), 115-121.

Chen, W., Kelly, M.A., Opitz-Araya, X., Thomas, R.E., Low, M.J., Cone, R.D., 1997. Exocrine gland dysfunction in MC5-R-deficient mice: evidence for coordinated regulation of exocrine gland function by melanocortin peptides. Cell 91(6), 789-798.

Cho, K.J., Shim, J.H., Cho, M.C., Choe, Y.K., Hong, J.T., Moon, D.C., Kim, J.W., Yoon, D.Y., 2005. Signaling pathways implicated in alpha-melanocyte stimulating hormone-induced lipolysis in 3T3-L1 adipocytes. J. Cell Biochem. 96(4), 869-878.

Daniels, D., Patten, C.S., Roth, J.D., Yee, D.K., Fluharty, S.J., 2003. Melanocortin receptor signaling through mitogen-activated protein kinase in vitro and in rat hypothalamus. Brain Res. 986(1-2), 1-11.

Davies, S.P., Reddy, H., Caivano, M., Cohen, P., 2000. Specificity and mechanism of action of some commonly used protein kinase inhibitors. Biochem. J. 351(Pt 1), 95-105. Ferreira, J.G., Cruz, C., Vinson, G.P., Pignatelli, D., 2004. ACTH modulates ERK phosphorylation in the adrenal gland in a time-dependent manner. Endocr. Res. 30(4), 661-666.

Gao, Z., Chen, T., Weber, M.J., Linden, J., 1999. A2B Adenosine and P2Y2 Receptors Stimulate Mitogen-activated Protein Kinase in Human Embryonic Kidney-293 Cells. Cross-talk between cyclic AMP and protein kinase C pathways. J. Biol. Chem. 274(9), 5972-5980.

Getting, S.J., 2006. Targeting melanocortin receptors as potential novel therapeutics. Pharmacology \& Therapeutics 111, 1-15.

Green, C.J., Göransson, O., Kular, G.S., Leslie, N.R., Gray, A., Alessi, D.R., Sakamoto, K., Hundal, H.S., 2008. Use of Akti and a drug-resistant mutant validates a critical role for $\mathrm{PKB} / \mathrm{Akt}$ in the insulin-dependent regulation of glucose and System A amino acid uptake. J. Biol. Chem. 283(41), 27653-27667.

Griffon, N., Mignon, V., Facchinetti, P., Diaz, J., Schwartz, J.C., Sokoloff, P., 1994. Molecular cloning and characterization of the rat fifth melanocortin receptor. Biochem. Biophys. Res. Commun. 200(2), 1007-1014.

Hoogduijn, M.J., McGurk, S., Smit, N.P., Nibbering, P.H., Ancans, J., van der Laarse, A., Thody, A.J., 2002. Ligand-dependent activation of the melanocortin 5 receptor: cAMP production and ryanodine receptor-dependent elevations of $[\mathrm{Ca}(2+)](\mathrm{I})$. Biochem. Biophys. Res. Commun. 290(2), 844-850.

Janes, M.E., Chu, K.M., Clark, A.J., King, P.J., 2008. Mechanisms of adrenocorticotropin-induced activation of extracellularly regulated kinase $1 / 2$ mitogenactivated protein kinase in the human H295R adrenal cell line. Endocrinology 149(4), 1898-1905.

Laemmli, U.K., 1970. Cleavage of structural proteins during the assembly of the head of bacteriophage T4. Nature 227, 680-685. 
Mandrika, I., Petrovska, R., Wikberg, J., 2005. Melanocortin receptors form constitutive homo- and heterodimers. Biochem. Biophys. Res. Commun. 326(2), 349-354.

Millington, G.W., 2006. Proopiomelanocortin (POMC): the cutaneous roles of its melanocortin products and receptors. Clin. Exp. Dermatol. 31(3), 407-412.

Mountjoy, K.G., Kong, P.L., Taylor, J.A., Willard, D.H., Wilkison, W.O., 2001. Melanocortin receptor-mediated mobilization of intracellular free calcium in HEK293 cells. Physiol. Genomics 5(1), 11-19.

Murphy, L.O., Blenis, J., 2006. MAPK signal specificity: the right place at the right time. Trends Biochem. Sci. 31(5), 268-275.

New, D.C., Wong, Y.H., 2007. Molecular mechanisms mediating the G protein-coupled receptor regulation of cell cycle progression. J. Mol. Signal 2, 2.

Nickolls, S.A., Maki, R.A., 2006. Dimerization of the melanocortin 4 receptor: A study using bioluminescence resonance energy transfer. Peptides 27, 380-387.

Park, H.J., Kim, H.J., Lee, J.Y., Cho, B.K., Gallo, R.L., Cho, D.H., 2007. Adrenocorticotropin hormone stimulates interleukin-18 expression in human $\mathrm{HaCaT}$ keratinocytes. J. Invest. Dermatol. 127(5), 1210-1216.

Pignatelli, D., Maia, M., Castro, A.R., da Conceição Magalhães, M., Vivier, J., Defaye, G., 2000. Chronic stress effects on the rat adrenal cortex. Endocr. Res. 26, 537-544.

Sánchez-Laorden, B.L., Sánchez-Más, J., Martínez-Alonso, E., Martínez-Menárguez, J.A., García-Borrón, J.C., Jiménez-Cervantes, C., 2006. Dimerization of the human melanocortin 1 receptor: functional consequences and dominant-negative effects. J. Invest. Dermatol. 126(1), 172-181.

Schulte, G., Fredholm, B.B., 2003. The G(s)-coupled adenosine A(2B) receptor recruits divergent pathways to regulate ERK1/2 and p38. Exp. Cell Res. 290(1), 168-176.

Schulte, G., Levy, F.O., 2007. Novel aspects of G-protein-coupled receptor signaling different ways to achieve specificity. Acta Physiol. 190, 33-38.

Schwindinger, W.F., Robishaw, J.D., 2001. Heterotrimeric G-protein $\beta \gamma$-dimers in growth and differentiation. Oncogene 20, 1653-1660.

Sun, Y., McGarrigle, D., Huang, X.-Y., 2007. When a G protein-coupled receptor does not couple to a $\mathrm{G}$ protein. Mol. BioSyst. 3, 849-854.

Vongs, A., Lynn, N.M., Rosenblum, C.I., 2004. Activation of MAP kinase by MC4-R through PI3 kinase. Regul. Pept. 120(1-3), 113-118.

Zanna, P.T., Sánchez-Laorden, B.L., Pérez-Oliva, A.B., Turpín, M.C., Herraiz, C., Jiménez-Cervantes, C., García-Borrón, J.C., 2008. Mechanism of dimerization of the human melanocortin 1 receptor. Biochem. Biophys. Res. Commun. 368(2), 211-216.

Zhang, L., Li, W.H., Anthonavage, M., Eisinger, M., 2006. Melanocortin-5 receptor: a marker of human sebocyte differentiation. Peptides 27(2), 413-420. 

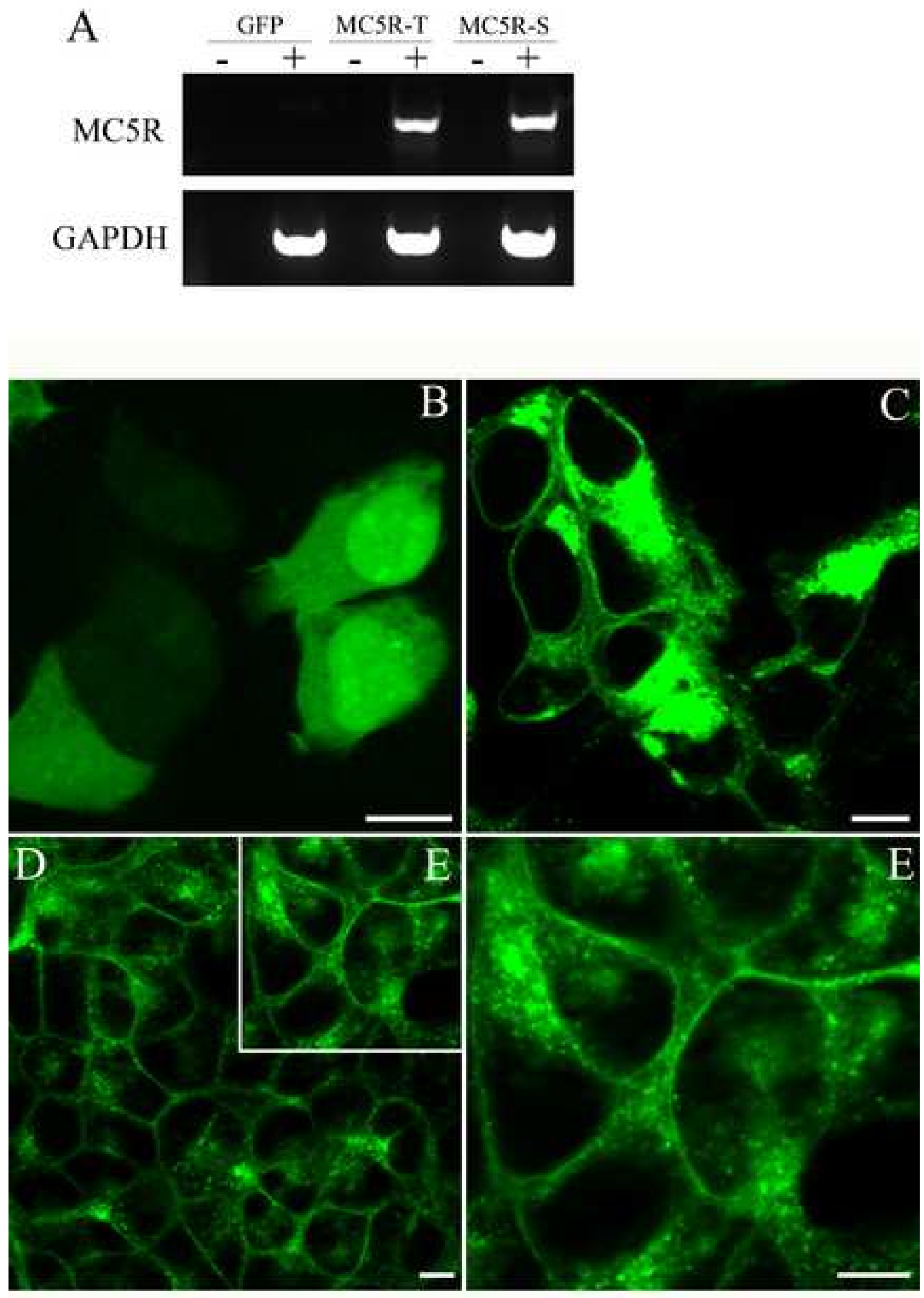

Figure 1 

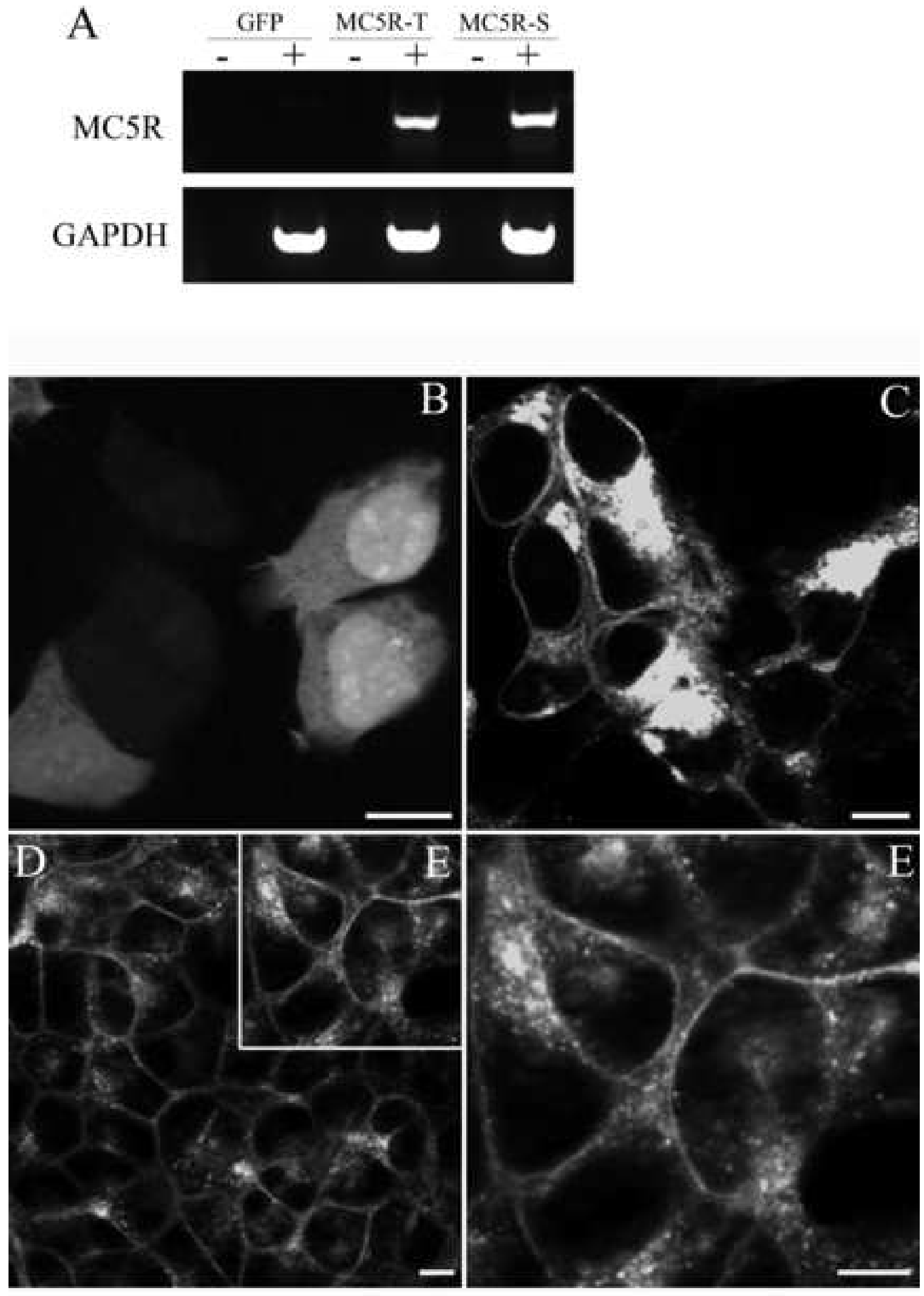

Figure 1 


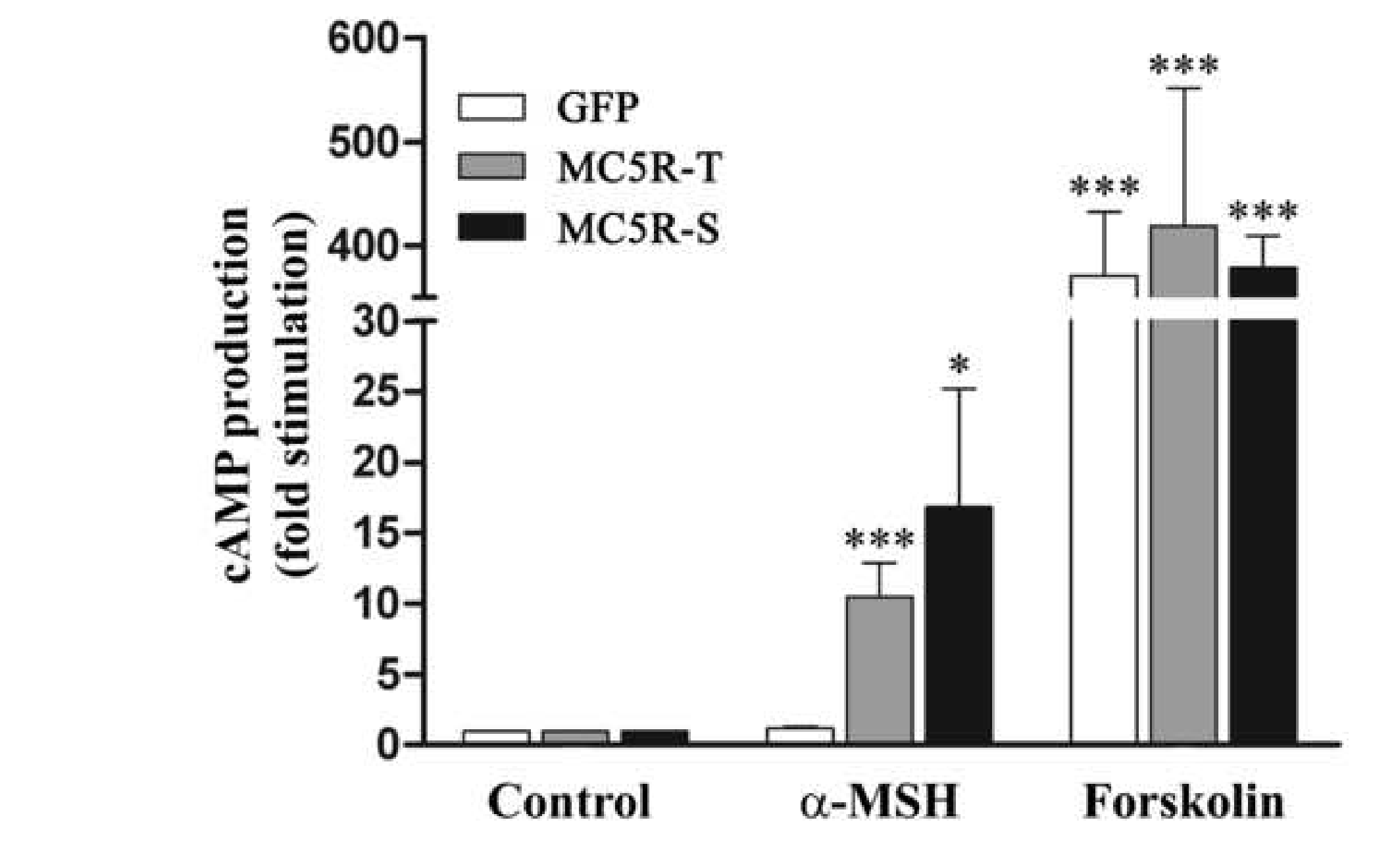

\section{Figure 2}

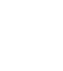

(19) 
A

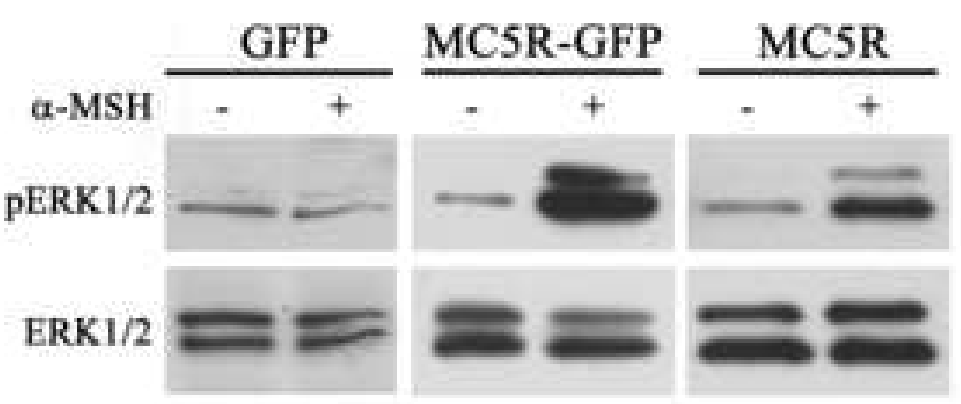

B

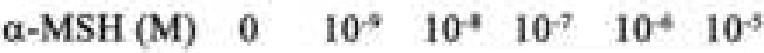

$$
\begin{aligned}
& \mathrm{pERK} 1 / 2=\mathrm{m}=\mathrm{m} \\
& \text { ERK } 1 / 2=0=0
\end{aligned}
$$

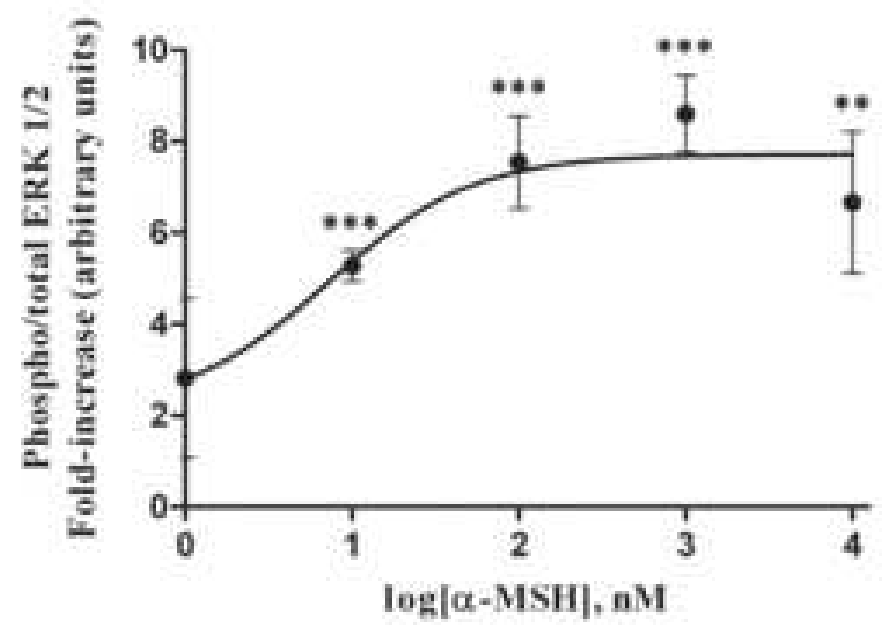

C
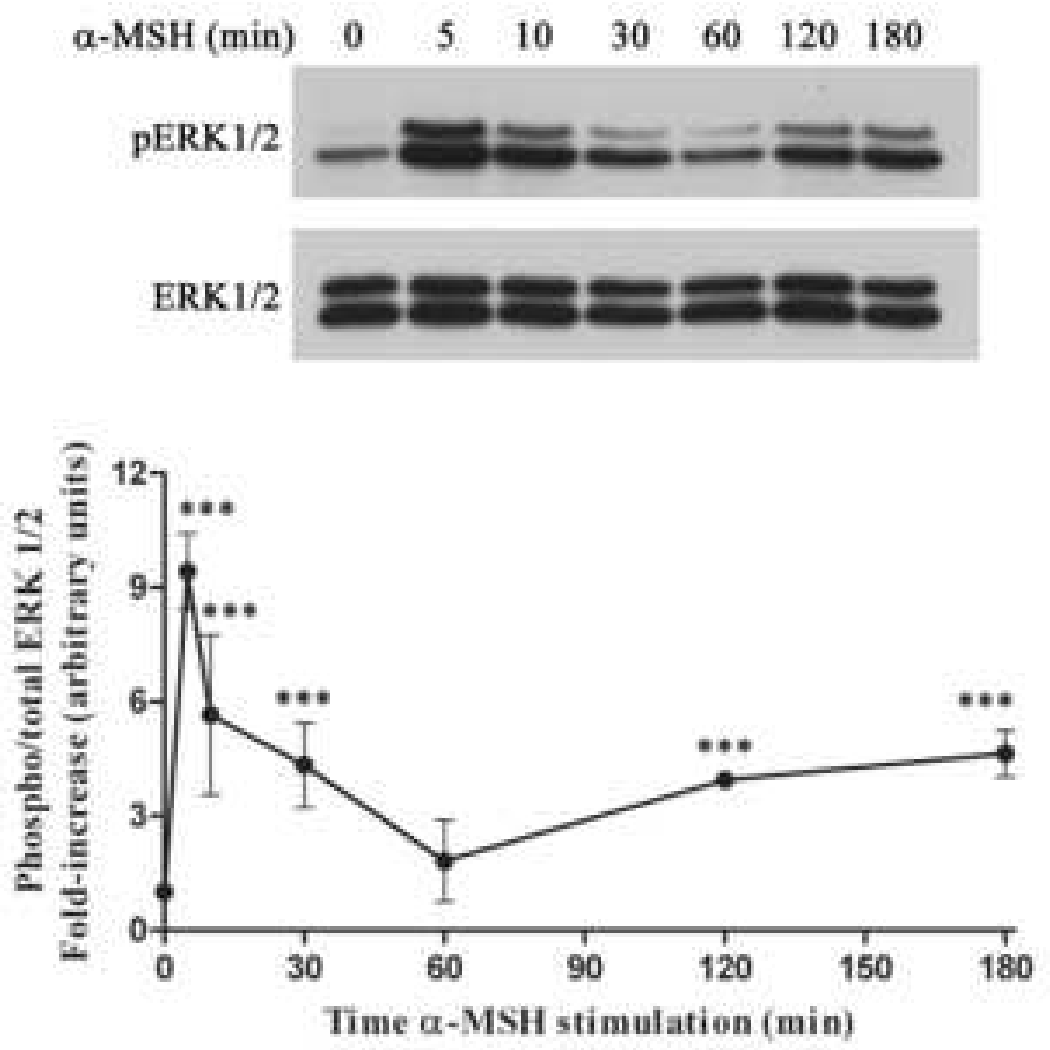

Figure 3 
A
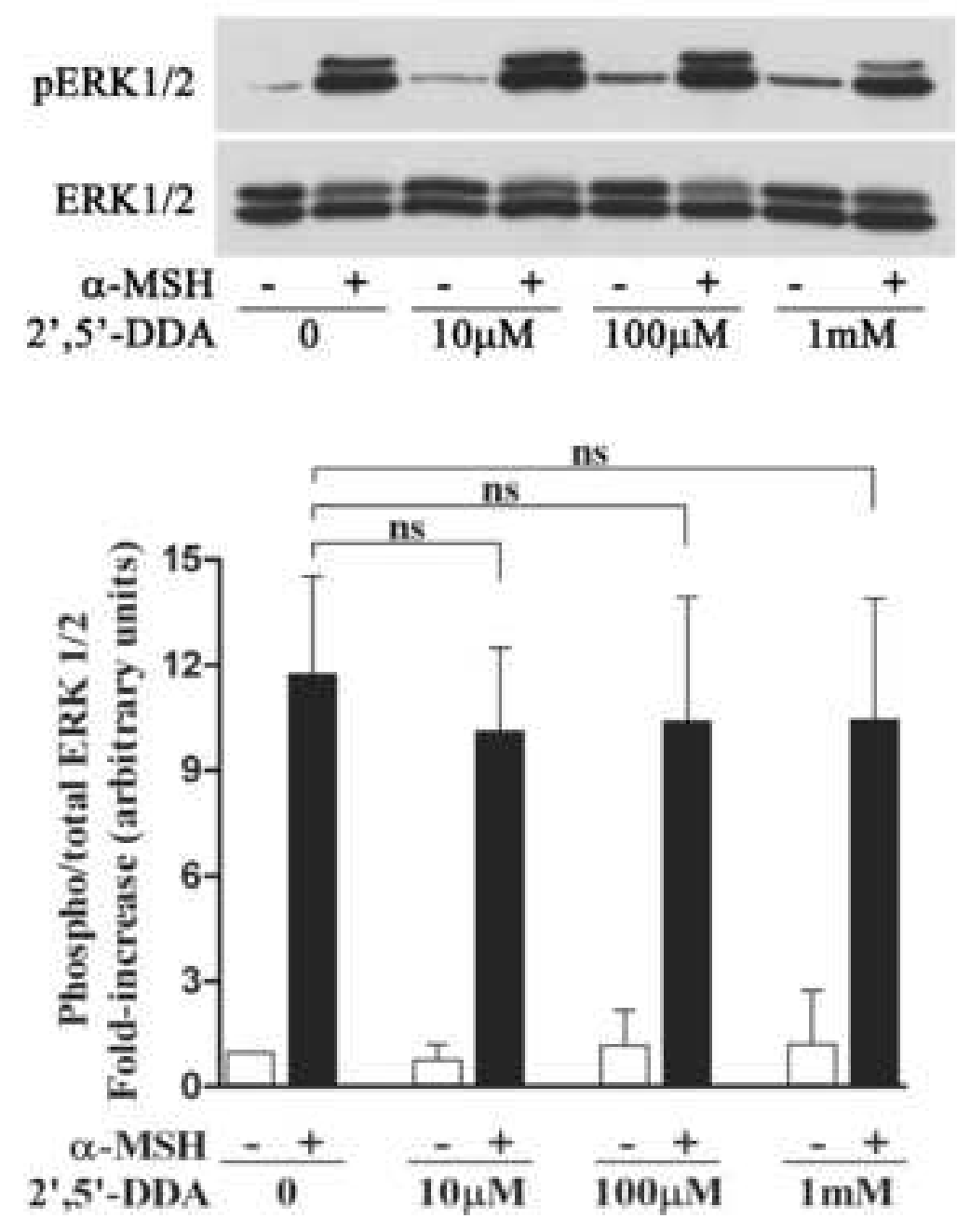

B
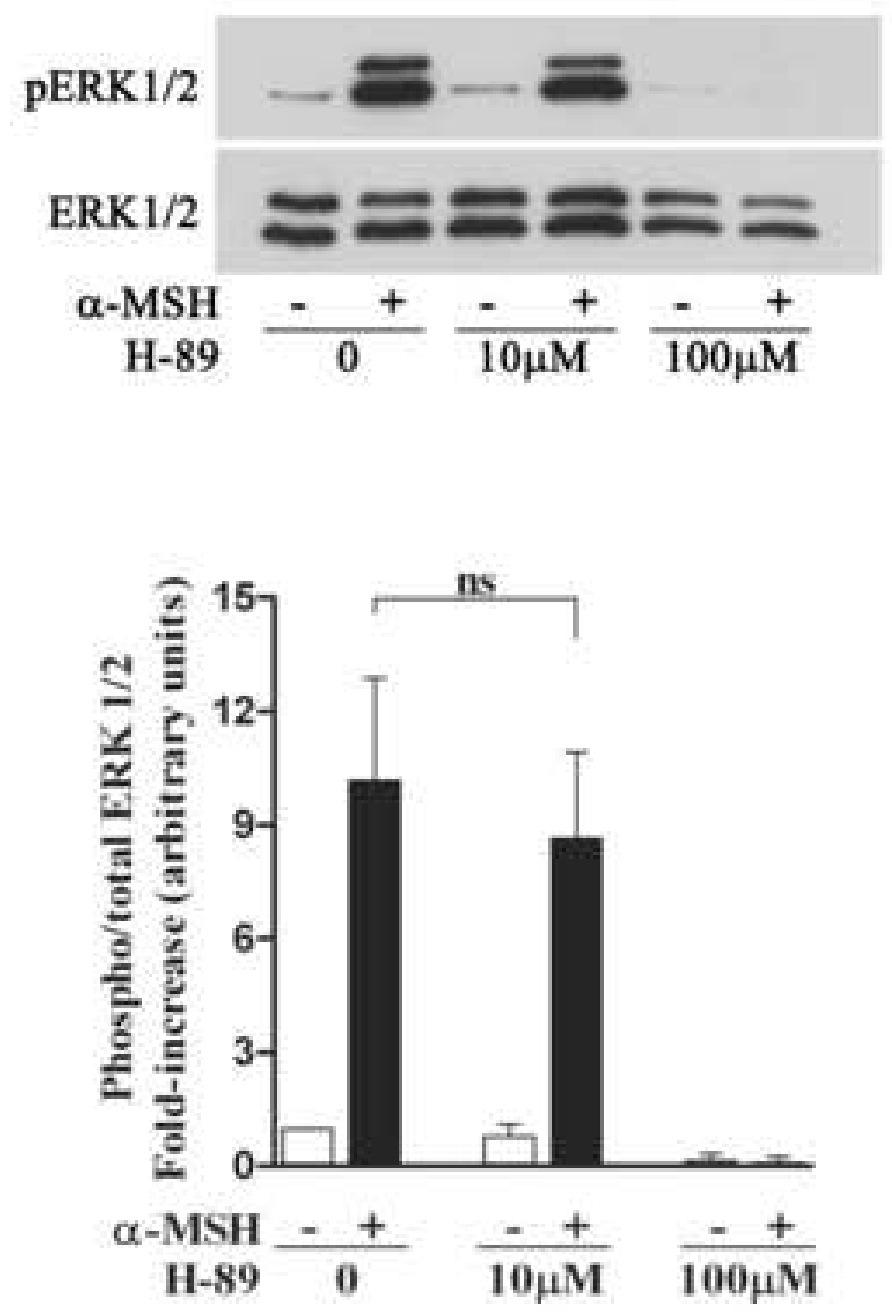

Figure 4 


\section{pERK1/2}

ERK1/2

$\alpha-\mathrm{MSH}$
$\mathrm{GF} 109203 \mathrm{X}$

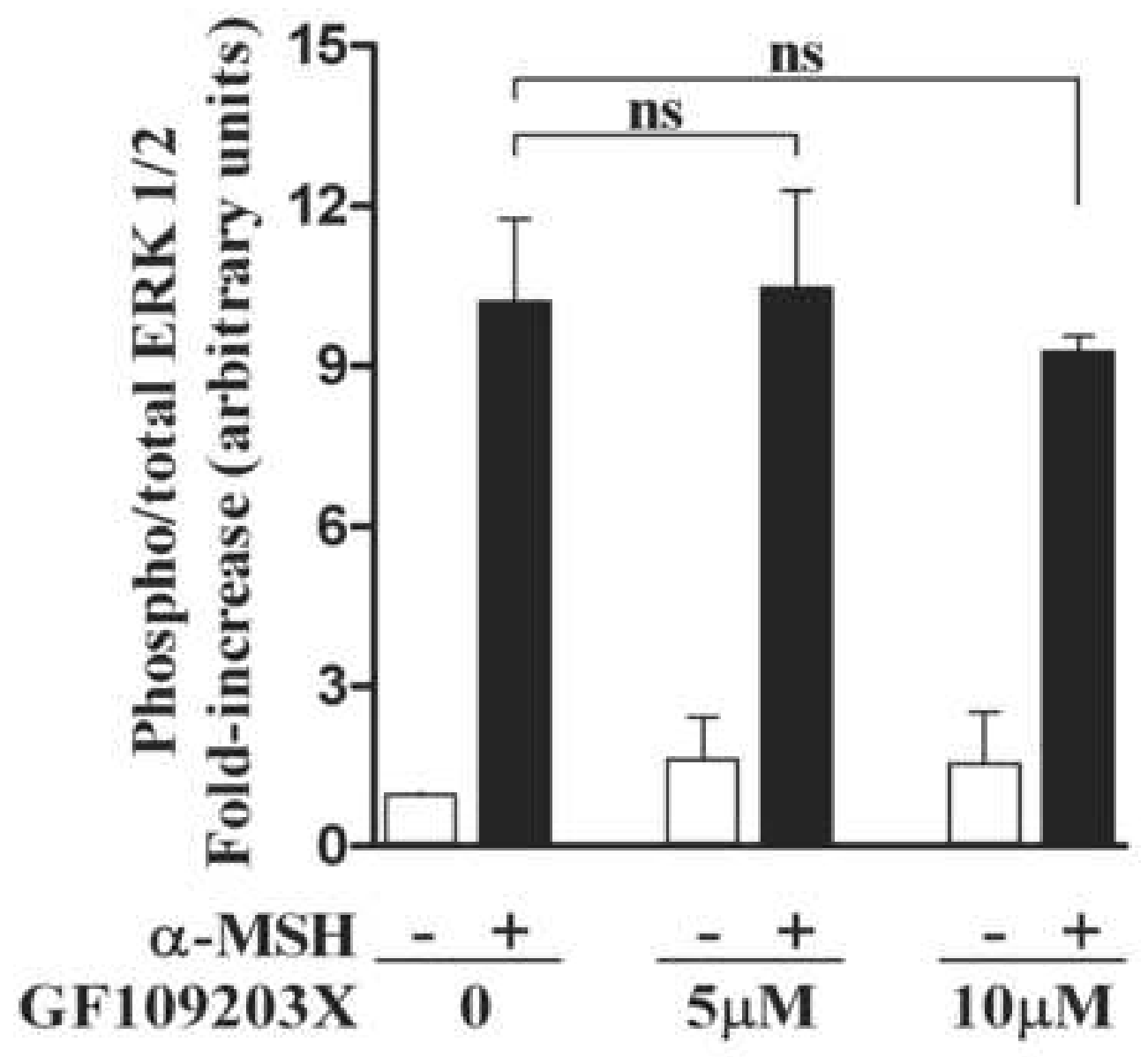

Figure 5 
A
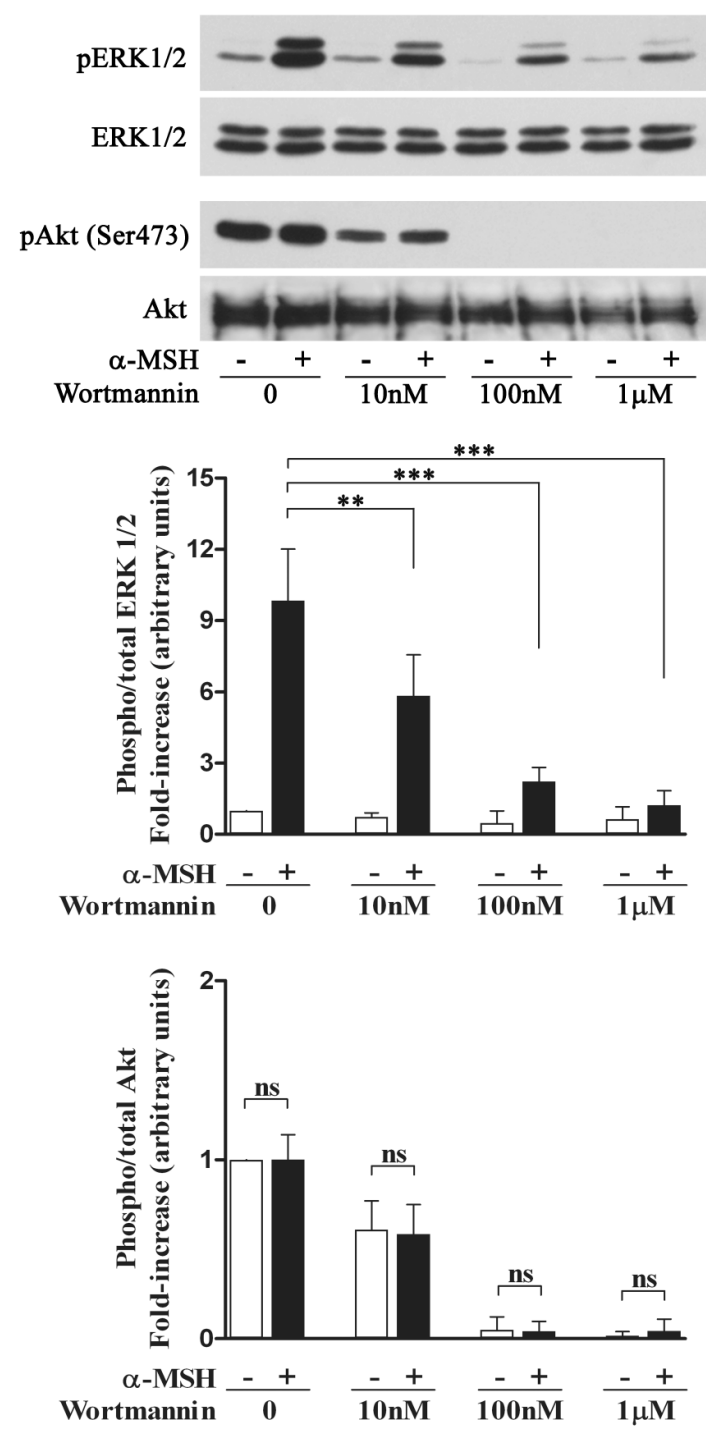

B
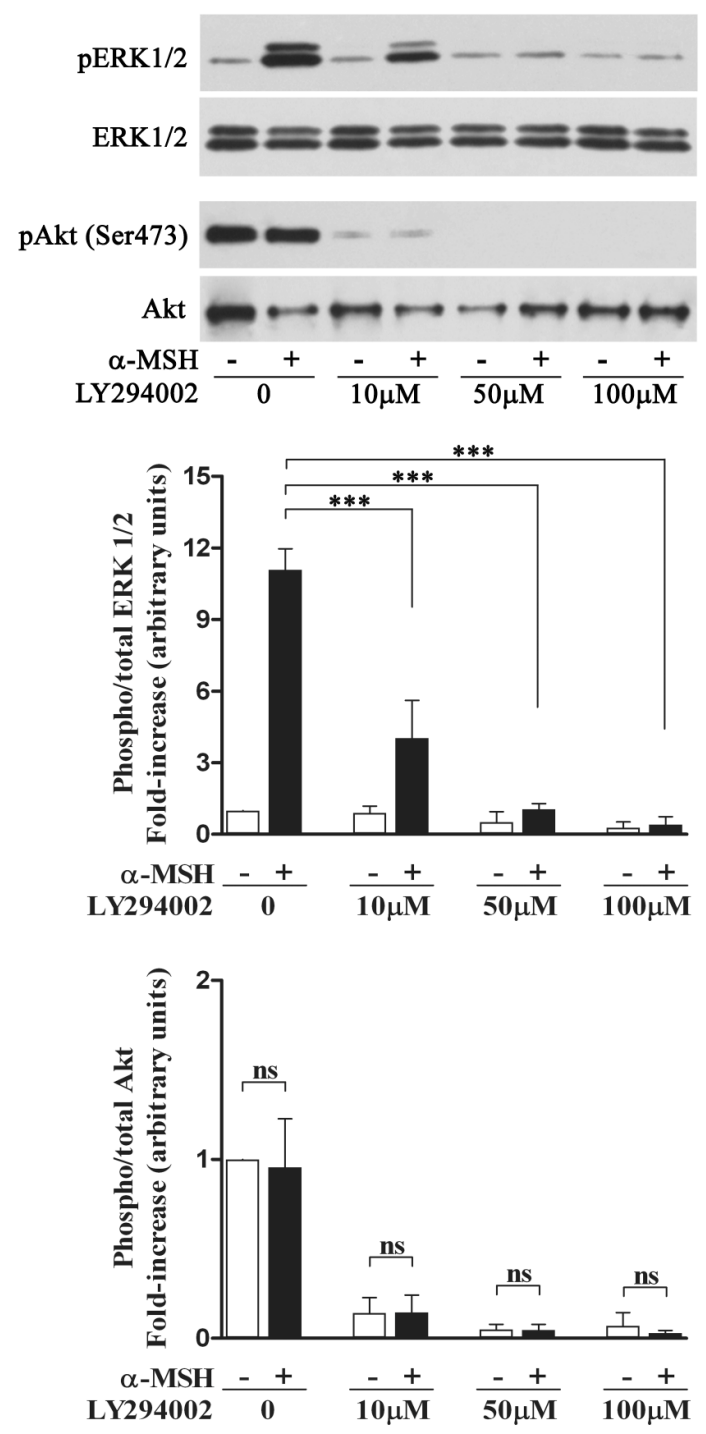

Figure 6 


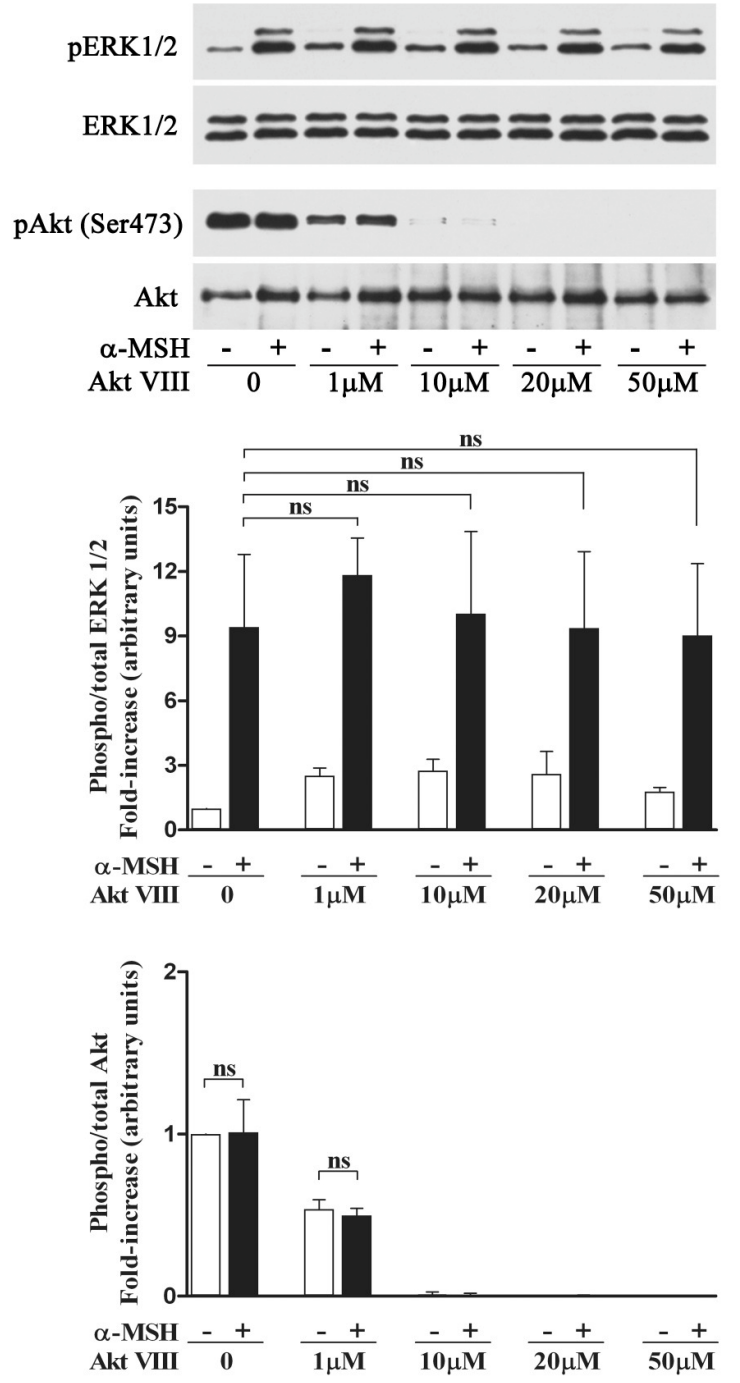

Figure 7 